\title{
A Pilot Study to Assess the Effects of Tai Chi on Health Indicators in Type 1 Diabetes Patients
}

\author{
Xin Liu 1,2,3*, Anthony Russell2,4, Enamul Kabir5, Wendy Brown ${ }^{6}$ \\ ${ }^{1}$ Wuhan Sport University, Wuhan, China \\ ${ }^{2}$ The University of Queensland School of Medicine, Brisbane, Australia \\ ${ }^{3}$ Beijing University of Chinese Medicine School of Life Sciences, Beijing, China \\ ${ }^{4}$ Department of Diabetes and Endocrinology, Princess Alexandra Hospital, Brisbane, Australia \\ ${ }^{5}$ School of Agricultural, Computational and Environmental Sciences, University of Southern Queensland, Toowoomba, Australia \\ ${ }^{6}$ The University of Queensland School of Human Movement and Nutrition Sciences, Brisbane, Australia \\ Email: *xin.liu@uqconnect.edu.au
}

How to cite this paper: Liu, X., Russell, A., Kabir, E. and Brown, W. (2019) A Pilot Study to Assess the Effects of Tai Chi on Health Indicators in Type 1 Diabetes Patients. Health, 11, 341-350.

https://doi.org/10.4236/health.2019.113030

Received: January 14, 2019

Accepted: March 22, 2019

Published: March 25, 2019

Copyright () 2019 by author(s) and Scientific Research Publishing Inc. This work is licensed under the Creative Commons Attribution International License (CC BY 4.0).

http://creativecommons.org/licenses/by/4.0/

\begin{abstract}
Objective: Previous studies have shown that Tai Chi may have a role in the management of type 2 diabetes. However, to date, no studies have focused specifically on the effects of Tai Chi in people with type 1 diabetes. The aim of this pilot study was to evaluate the effects of a Tai Chi program on health indicators in adults with type 1 diabetes. Methods: This was a two-group quasi-randomised controlled trial with 13 participants (six men and seven women, aged $24-63$ years) with type 1 diabetes. This trial was conducted from May to November 2016. The intervention group attended Tai Chi exercise training for 1 to 1.5 hours, twice a week for 12 weeks, and the control group continued with their usual medical care. Indicators of glycaemic control (HbAlc), depressive symptoms, physical measures (body mass index, waist circumference, blood pressure and leg strength), and health-related quality of life (physical and mental components summary scores) were assessed at baseline and 12 weeks' post-intervention. Results: There were significant or borderline significant between-group differences in changes over time in favour of the intervention group in depressive symptoms $(\mathrm{p}<0.01)$, waist circumfereance $(\mathrm{p}=0.059)$, mental components summary score $(\mathrm{p}=0.051)$ and leg strength $(p<0.05)$ during the 12 weeks' intervention. Further, compared with baseline, significant improvements were observed in depressive symptoms ( $\mathrm{p}$ $<0.05)$, mental components summary score $(\mathrm{p}<0.05)$ and leg strength $(\mathrm{p}<$ 0.01 ) in the intervention group, but not in the control group. In contrast, there was a significant increase in waist circumference in the control group ( $\mathrm{p}$ $<0.05)$ but not in the intervention group. Conclusion: In conclusion, there were improvements in mental health and leg strength in these adults with type 1 diabetes. Large studies are needed to further investigate the effects of
\end{abstract}


Tai Chi in people with Type 1 diabetes.

\section{Keywords}

Tai Chi, Exercise, Type 1 Diabetes

\section{Introduction}

Between $10 \%$ and $15 \%$ of people with diabetes have type 1 diabetes (T1D). As it is a chronic disease, T1D is also associated with increased risk of depressive disorders [1]. The prevalence of depression among people with type 1 diabetes $(20 \%-27 \%)$ is at least two to three times greater than the $5 \%-8 \%$ background rate of depression reported for those who are non-diabetic [2]. Depression, in combination with diabetes, is associated with poorer diabetes control, increased diabetes-related complications, increased frequency of emergency department visitation and hospitalisations, greater functional impairment, increased suicidality and higher healthcare costs [3] [4] [5] [6]. Improvements in mental health may therefore be associated with management in glycaemic control in people with T1D. There is growing evidence of favourable effects of physical activity (including vigorous intensity exercise and resistance training) on glycaemic control in people with T1D [7] [8]. Tai Chi, being a gentle and low impact mind-body exercise, has been shown to improve both glycaemic control and depressive symptoms in people with type 2 diabetes [9] [10] [11], suggesting that it may have a role in managing glycaemic control, and improving mental health in adults with T1D. However, to date, no studies have focused specifically on the effects of Tai Chi in people with T1D. This pilot study examined the effects of a Tai Chi program on indicators of glycaemic control, mental health, health-related quality of life and physical measures (including body mass index, waist circumference, blood pressure and leg strength), in adults with T1D.

\section{Methods}

The methods were similar to those described in an earlier paper [12].

\subsection{Participants and Study Design}

Ethical clearances were obtained from the Metro South Hospital and Health Service Human Research Ethics Committee at Princess Alexandra Hospital and the Human Research Ethics Committee at The University of Queensland (Australia). It was a two-group quasi-randomised controlled trial, conducted from May to November 2016. Outcome measures were assessed at baseline and 12 weeks after intervention. Participants with T1D were randomly allocated to the Tai Chi intervention, or to the usual care control group, based on recruitment date. Due to logisitic constraints, the first six participants were assigned to the intervention group. The control group was offered the Tai Chi program at the end of the 
study. We recruited participants through referral from endocrinologists at the Department of Diabetes and Endocrinology of the Princess Alexandra Hospital, as well as letters of invitation to members of Diabetes Australia Queensland. Inclusion criteria were: type 1 diabetes with HbAlc of 7.5\% - 10\%, on stable insulin therapy; aged 18 - 70 years; no health or injury problems that would prevent doing the exercises; able to attend intervention sessions 2 times per week for 12 weeks; and living in Brisbane. From 39 potential participants, 13 were eligible to participant in the study (see Figure 1). Before attending the baseline assessment, all participants were cleared by their Endocronologist/General Practitioner, and signed the consent form to participate in the study.

\subsection{The Intervention}

During the 12 week study, the Tai Chi group attended group training twice a week, conducted by an experienced Tai Chi instructor. The intervention group also practiced at home using the Tai Chi program DVD provided by the study, on days when they did not attend the group training. The exercise employed in this study was KaiMai Tai Chi style [13]. Each training session consisted of

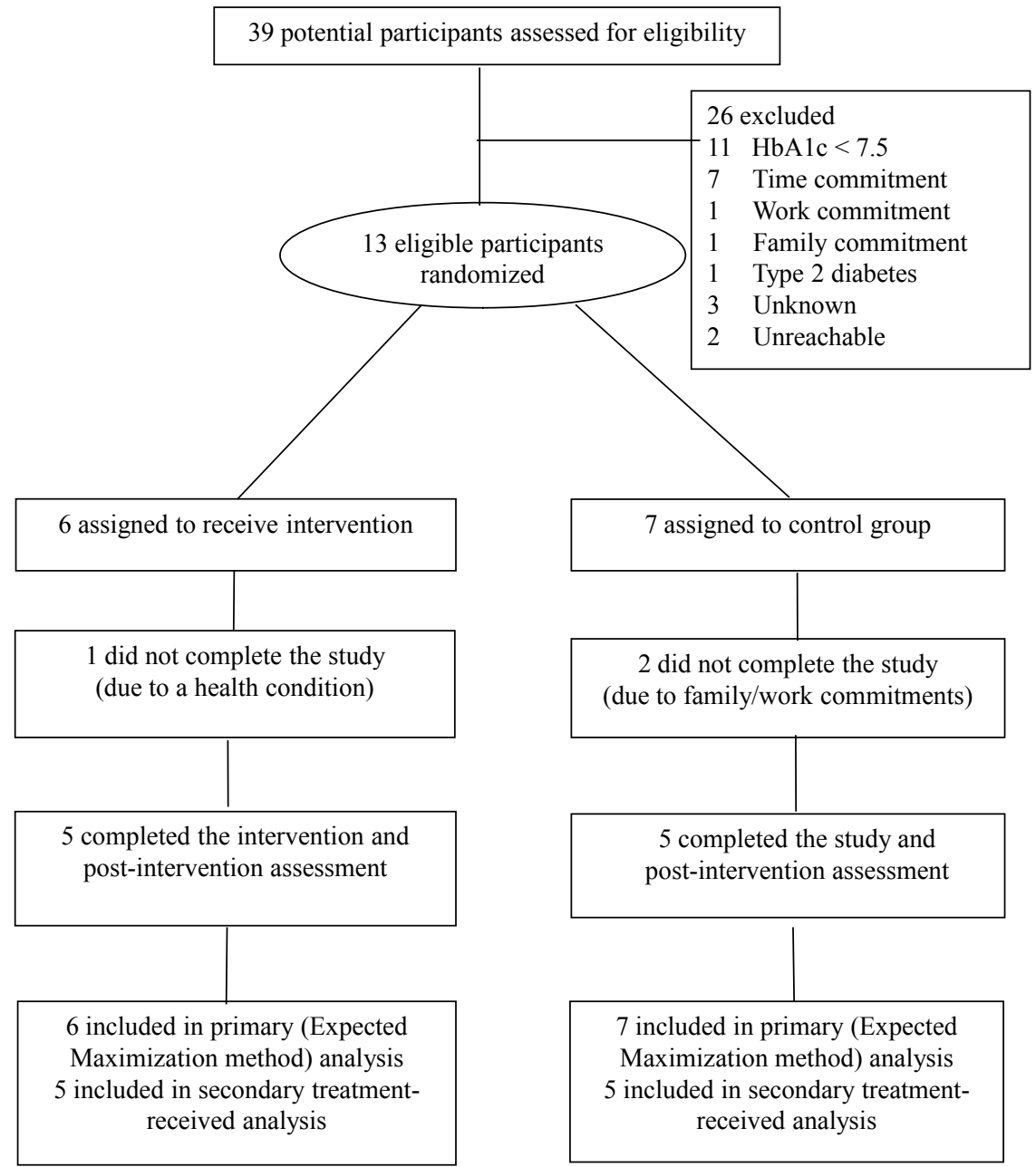

Figure 1. Flow of participants through the study. 
warm up, practice and cool down and lasted for around 1.5 hours. The intensity of the training was individualized according to each participant's health condition.

\subsection{Measures}

All participants provided written informed consent prior to baseline assessment. The baseline assessment was conducted at the Princess Alexandra Hospital by an independent research assistant (including blood sample collection, questionnaire and physical measures), followed by the same assessment at 12 weeks.

The primary outcomes included HbAlc (assessed from a fasting venous blood sample) and depressive symptoms (using the short form of the CES-D Depressive Scale 10) [14]. The secondary outcomes included physical measures and quality of life (QOL). Waist circumference, height and weight were measured using standard protocols [15]. Body mass index (BMI) was calculated as weight ( $\mathrm{kg}$ ) divided by height squared $\left(\mathrm{m}^{2}\right)$. Resting blood pressure was measured using standard protocols [16] [17]. QOL was assessed using the Medical Outcomes Study 36-Item Short-Form Health Survey (SF-36) [18]. Leg strength was assessed using a chair-stand test (number of stands completed in 30 seconds) [19].

The questionnaire asked about age, gender, country of birth, family history of diabetes, language spoken at home, depressive symptoms, and health-related quality of life. The acceptability and feasibility of the Tai Chi program were also assessed using open-ended questions at post-intervention including perceived benefits of and barriers to participating in the program, and comments on the Tai Chi program DVD provided for at-home practice.

The group training instructor recorded the group session attendance, and reasons for non-attendance at each class. The at-home practice was recorded by the participants themselves using a diary during the intervention.

\subsection{Statistical Analyses}

All the statistical analyses were conducted in SPSS (Version 23). 13 participants participated in this study, with six assigned to the intervention group and seven to the control group. One from the intervention group and two from the control group were lost to follow up. Primary analyses were conducted using the Expected Maximization (EM) method to estimate missing values. Secondary analyses were also conducted using treatment-received analyses. Descriptive statistics were used to characterize participants at baseline and follow up. Independent samples t-tests were used to assess between group differences at baseline in outcome variables. One way repeated measures ANOVA was used to assess differences between groups in changes over time in each of the outcome variables.

\section{Results}

\subsection{Participant Characteristics}

Thirteen participants ( 6 men and 7 women, aged $24-63$ years old) participated 
in this pilot study. All except three were born in Australia, but all spoke English at home. The average age of diagnosis with T1D was 26 (range 5 - 48) years, with an average history of T1D of $16(2-31)$ years. HbAlc levels ranged from 7.5 to $9.2 \%$.

\subsection{Adherence, Acceptability and Feasibility}

Adherence to the program was good, with all intervention participants except one retained during the 12 week program (Figure 1). On average participants attended $83 \%$ of the group classes, with absence mainly attributed to competing family or work commitments. Two participants in the control group dropped out during the study (Figure 1).

Participants reported both physical and psychological benefits from the program. Perceived physical benefits included "knees feeling better" and "getting sore less", "starting to get thigh muscles", "more energy", "sleeping better", "improved flexibility" and "improved wellbeing". Reported psychological benefits included feeling "happier", "more calm", "better concentration", and "more confidence in managing and talking about T1D". Participants reported "feeling more positive and more active", "improved coping" and "less stress" (particularly at work). All participants reported that the DVD was useful for their learning and training, with comments indicating that it assisted with memorising the movements.

\subsection{Changes in Primary Outcomes}

There were no between group differences in the demographic or outcome variables at baseline.

Changes in $\mathrm{HbAlc}$ and depressive symptoms from baseline to post-intervention in each group are shown in Table 1 and Figure 2. There was no change in $\mathrm{HbAlC}$ in either group. There was however a small but significant improvement in depressive symptoms in the intervention group $(\mathrm{p}<0.01)$ and a concomitant worsening in the control group $(\mathrm{p}<0.05)$ (see Table 1). Individual data showed an improvement in depressive symptoms in 4 of the 6 intervention participants and slightly worsening symptoms in all but one of the control group (see Figure 2).

\subsection{Changes in Secondary Outcomes}

Changes in physical measures and quality of life from baseline to post-intervention are also shown in Table 1 and Figure 2. The only between group differences in changes over time were in waist circumference $(p=0.059)$, mental components summary score $(\mathrm{p}=0.051)$ and leg strength $(\mathrm{p}<0.05)$. Although there was no significant improvement in waist circumference in the intervention group, this measure increased significantly (worsened) in the control group $(\mathrm{p}<0.05)$. There were improvements in the mental health summary score $(\mathrm{p}<0.05)$ and leg strength measure in the intervention group $(\mathrm{p}<0.01)$ but not in the control group (Table 1). 
Table 1. Changes in Primary and Secondary Outcomes from Baseline to 12 Weeks Post-intervention $(\mathrm{N}=13)$.

\begin{tabular}{|c|c|c|c|c|c|c|c|}
\hline \multirow[t]{3}{*}{ Outcomes } & \multicolumn{3}{|c|}{ Intervention } & \multicolumn{3}{|c|}{ Control } & \multirow{3}{*}{$\begin{array}{c}\text { Between-group } \\
\text { difference in } \\
\text { changes over time }\end{array}$} \\
\hline & Baseline & Post-intervention & Mean difference & Baseline & Post-interventior & Mean difference & \\
\hline & $\begin{array}{l}\text { Mean } \\
(\mathrm{SD})\end{array}$ & $\begin{array}{c}\text { Mean } \\
(\mathrm{SD})\end{array}$ & $\begin{array}{l}\text { Mean } \\
(\mathrm{CI})\end{array}$ & $\begin{array}{c}\text { Mean } \\
(S D)\end{array}$ & $\begin{array}{l}\text { Mean } \\
(\mathrm{SD})\end{array}$ & $\begin{array}{l}\text { Mean } \\
(\mathrm{CI})\end{array}$ & \\
\hline \multicolumn{8}{|l|}{ Primary outcomes } \\
\hline HbAlc (\%) & $7.97(0.28)$ & $8.21(0.51)$ & $\begin{array}{c}0.24 \\
(-0.33 ; 0.81)\end{array}$ & $8.46(0.61)$ & $8.59(0.66)$ & $\begin{array}{c}0.24 \\
(-0.40 ; 0.67)\end{array}$ & 0.758 \\
\hline $\begin{array}{l}\text { Depressive symptoms } \\
\text { (score) }\end{array}$ & $22.5(8.02)$ & $19.17(4.28)$ & $\begin{array}{c}-3.33^{*} \\
(-6.30 ;-0.35)\end{array}$ & $17.71(5.09)$ & $20.53(4.00)$ & $\begin{array}{c}2.81^{*} \\
(0.06 ; 5.57)\end{array}$ & $0.007^{*}$ \\
\hline \multicolumn{8}{|l|}{ Secondary outcomes } \\
\hline BMI $\left(\mathrm{kg} / \mathrm{m}^{2}\right)$ & $24.26(3.69)$ & $24.51(3.71)$ & $\begin{array}{c}0.25 \\
(-1.83 ; 2.33)\end{array}$ & $26.46(3.48)$ & $27.09(2.75)$ & $\begin{array}{c}0.63 \\
(-1.30 ; 2.56)\end{array}$ & 0.773 \\
\hline $\begin{array}{l}\text { Waist circumference } \\
\qquad(\mathrm{cm})\end{array}$ & $87.55(5.36)$ & $86.41(6.00)$ & $\begin{array}{c}-1.14 \\
(-4.25 ; 1.98)\end{array}$ & $92.81(8.51)$ & $95.74(9.86)$ & $\begin{array}{c}2.93^{*} \\
(0.05 ; 5.82)\end{array}$ & $0.059^{*}$ \\
\hline $\begin{array}{c}\text { Systolic blood } \\
\text { pressure (mm Hg) }\end{array}$ & $\begin{array}{l}119.61 \\
(15.39)\end{array}$ & $116.37(5.48)$ & $\begin{array}{c}-2.84 \\
(-23.77 ; 18.10)\end{array}$ & $129.48(18.94)$ & $128.31(17.90)$ & $\begin{array}{c}-1.17 \\
(-20.55 ; 18.77)\end{array}$ & 0.900 \\
\hline $\begin{array}{c}\text { Diastolic blood } \\
\text { pressure }(\mathrm{mm} \mathrm{Hg})\end{array}$ & $77.72(9.85)$ & $74.72(4.74)$ & $\begin{array}{c}-3.00 \\
(-12.96 ; 6.95)\end{array}$ & $75.67(6.17)$ & $75.68(6.81)$ & $\begin{array}{c}0.13 \\
(-9.2 ; 9.23)\end{array}$ & 0.634 \\
\hline $\begin{array}{l}\text { Physical components } \\
\text { summary score (score) }\end{array}$ & $38.30(7.99)$ & $38.98(6.04)$ & $\begin{array}{c}0.68 \\
(-5.70 ; 7.07)\end{array}$ & $40.99(5.68)$ & $40.64(3.64)$ & $\begin{array}{c}-0.35 \\
(-6.26 ; 5.56)\end{array}$ & 0.799 \\
\hline $\begin{array}{l}\text { Mental components } \\
\text { summary score (score) }\end{array}$ & $39.47(9.67)$ & $49.14(3.15)$ & $\begin{array}{c}9.66^{*} \\
(2.61 ; 16.72)\end{array}$ & $46.04(8.58)$ & $46.14(4.92)$ & $\begin{array}{c}0.11 \\
(-6.43 ; 6.64)\end{array}$ & $0.051^{*}$ \\
\hline $\begin{array}{l}\text { Leg strength (number } \\
\text { of chair stand test) }\end{array}$ & $15.00(6.39)$ & $18.29(7.12)$ & $\begin{array}{c}3.23^{*} \\
(1.46 ; 5.12)\end{array}$ & $13.14(3.39)$ & $13.86(2.87)$ & $\begin{array}{c}0.72 \\
(-0.97 ; 2.42)\end{array}$ & $0.045^{*}$ \\
\hline
\end{tabular}

${ }^{\sharp}$ Results from Expected Maximization method of analysis; ${ }^{\star}$ Significant or borderline significant differences in changes over time.

Individual data indicated variable changes in BMI in both groups, with small improvements in 4 of 6 intervention, and 2 of 7 control participants (Figure 2). Similarly, while there were improvements in leg strength in 5 of the 6 participants in the intervention group, leg strength also improved slightly in 4 of the control group participants. However, the improvement was statistically significant in the intervention group, but not in the control group (Table 1).

The results described above were based on the primary Expected Maximization analysis method. These findings did not change with "treatment received" analyses, except that the latter demonstrated significant between-group effects in favour of the intervention group in $\operatorname{HbA1c}(\mathrm{p}<0.05)$ and waist circumference $(\mathrm{p}$ $<0.05)$.

\subsection{Changes in Medication}

Three participants made changes to their medication during the study. One participant in the intervention group changed one brand of insulin (Humalog) to another (Novorapid), but with the same dose. Two control participants made changes to their insulin regimens, by changing the dose or type of insulin used. 
Intervention
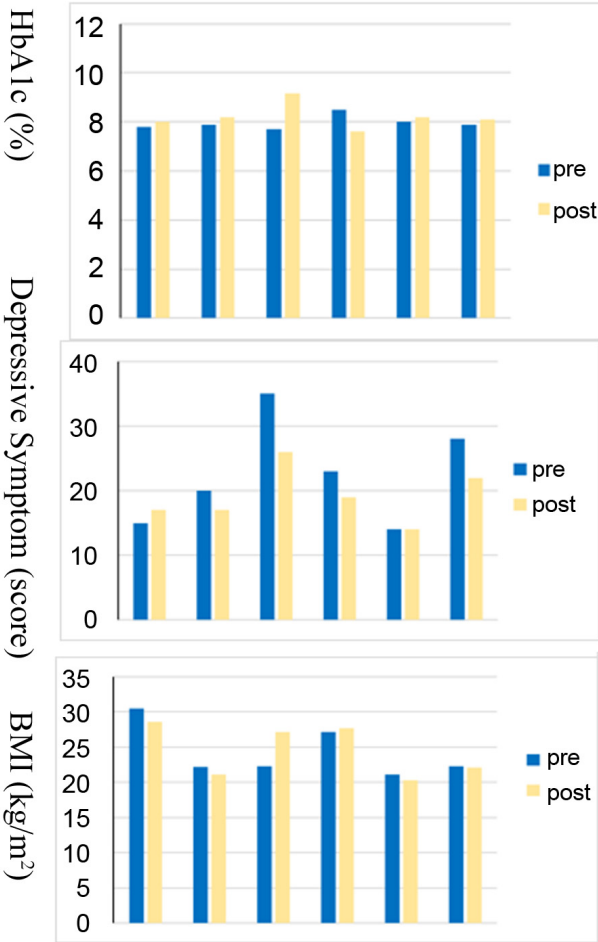

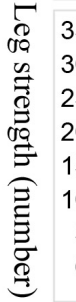

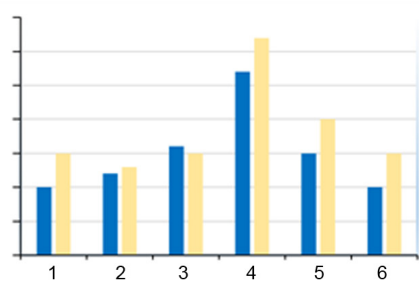

\section{Control}
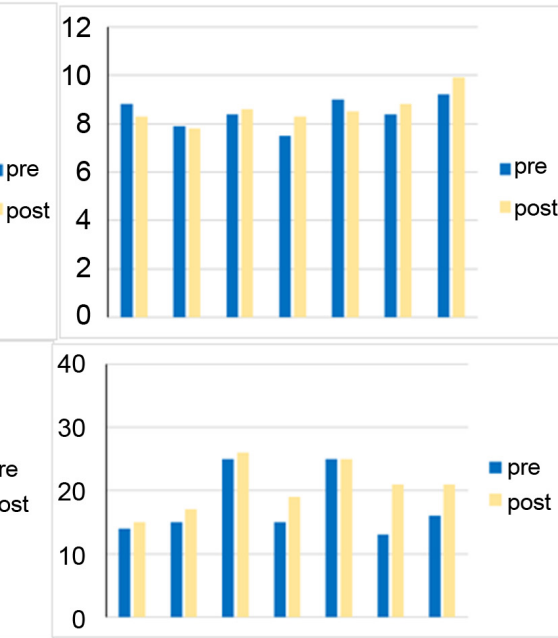

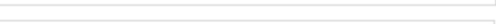
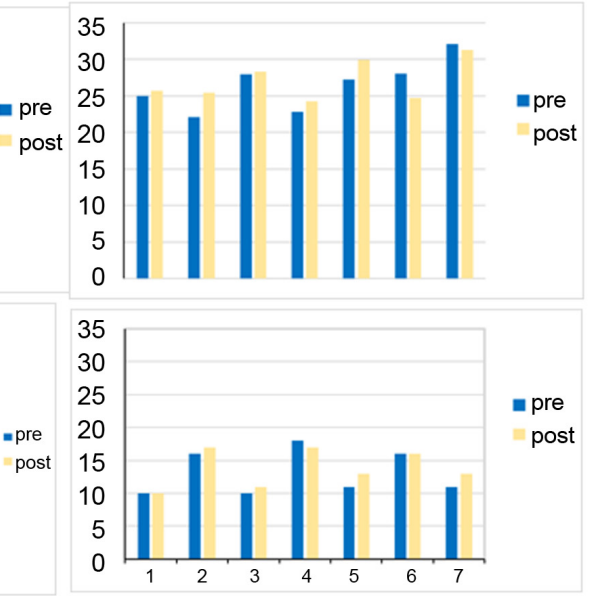

Participants

Figure 2. Individual Changes in HbA1c, Depressive Symptoms, Body Mass Index (BMI) and Leg Strength at Pre- and Post-12 Weeks Intervention (results from the Expected Maximization analysis method).

\section{Discussion}

This was the first study to investigate the effects of Tai Chi on health indicators in adults with T1D. There were significant or borderline significant between-group differences in changes over time, in favour of the intervention group, in depressive symptoms, waist circumference, mental components summary score and leg strength during the 12 week intervention. The involvement of many leg movements in Tai Chi training may explain the marked improvements in leg strength in the intervention group. This is important, because previous studies have shown that resistance training can improve glycaemic control, insulin sensitivity and cardiovascular risk factors in people with Type 2 diabetes [20] [21]. The improvement in leg strength may help the management of T1D, especially in the long term. In addition, the improvements in depressive symptoms and mental health are similar to those seen in previous Tai Chi/Qigong studies of adults with 
Type 2 diabetes [9] [10] [11] [22], and are consistent with the view that "positive mind" activities, which are central to Tai Chi training, can promote improved mental health in this patient group. This is important because there is evidenc showing the combination of depression and diabetes is associated with diabetes control and diabetes-related complications [3] [4] [5] [6].

Interestingly, although the between group difference was not quite statistically significant, there was a significant increase in waist circumference of almost 3 $\mathrm{cm}$ in the control group, but no change in the intervention group. This shows the potential of this Tai Chi program to control the development of central obesity in people with T1D. This is important because central obesity is integral to the definition and development of metabolic syndrome and diabetes [23]. It has also been reported that $15 \%$ of people with T1D fulfill the criteria for metabolic syndrome and are at higher risk of macrovascular complications [24]. Therefore, management of central obesity through Tai Chi intervention may also help reduce the risks of developing many other diseases.

This pilot study was limited by the small sample size, which resulted from challenges in recruiting for this study. Although local medical practitioners indicated their willingness to refer patients, few of the referred patients were willing to give their time to this study, especially if they were to be in the control group. This suggested that different study design and recruitment strategies may need to be considered in future studies.

The small sample size limited our ability to demonstrate statistically significant group differences in most variables, but the data showed indications of improvement in some important measures (including depressive symptoms, waist circumference, mental components summary score and leg strength) during the 12 week intervention. These observations support the view that Tai Chi may have a role to play in improving health outcomes in adults with T1D, if only they could be persuaded to do this form of exercise. The data on changes over time will be useful for determining sample sizes and power for future studies.

A second limitation is the study design. As the Tai Chi instructor was available for only a limited time, we had to start the intervention with the early participants, rather than randomly assign participants to groups on recruitment. However, there were no differences between the groups on any measure at baseline.

\section{Conclusion}

This pilot study of a 12-week Tai Chi intervention found improvements in mental health and leg strength in adults with T1D. The data support the need for larger well-designed studies to further investigate the effects of Tai Chi on health indicators in adults with T1D.

\section{Acknowledgements}

This research project was funded by a grant from the Diabetes Australia Re- 
search Trust (\#Y16G-LIUX). We would like to thank Diabetes Australia Queensland for their assistance with recruitment. We would also like to thank the participants for their commitment to this study.

\section{Conflicts of Interest}

The authors declare no conflicts of interest regarding the publication of this paper.

\section{References}

[1] Berge, L., Riise, T. and Hundal, O. (2013) Prevalence and Characteristics of Depressive Disorders in Type 1 Diabetes. BMC Research Notes, 19, 543. https://doi.org/10.1186/1756-0500-6-543

[2] Kovacs, M., Goldston, D., Obrosky, D.S. and Bonar, L.K. (1997) Psychiatric Disorders in Youths with IDDM: Rates and Risk Factors. Diabetes Care, 20, 36-44. https://doi.org/10.2337/diacare.20.1.36

[3] Lawrence, J.M., Standiford, D.A. and Loots, B. (2006) Prevalence and Correlates of Depressed Mood among Youth with Diabetes: The SEARCH for Diabetes in Youth study. Pediatrics, 117, 1348-1358. https://doi.org/10.1542/peds.2005-1398

[4] Stewart, S.M., Rao, U., Emslie, G.J., Klein, D. and White, P.C. (2005) Depressive Symptoms Predict Hospitalization for Adolescents with Type 1 Diabetes Mellitus. Pediatrics, 115, 1315-1319. https://doi.org/10.1542/peds.2004-1717

[5] Goldston, D.B., Kelley, A.E. and Reboussin, D.M. (1997) Suicidal Ideation and Behavior and Noncompliance with the Medical Regimen among Diabetic Adolescents. Journal of the American Academy of Child \& Adolescent Psychiatry, 36, 1528-1536.

[6] Leichter, S.B. and See, Y. (2005) Problems That Extend Visit Time and Cost in Diabetes Care: How Depressive May Affect the Efficacy and Cost of Care of Diabetic Patients. Clinical Diabetes, 23, 53-54. https://doi.org/10.2337/diaclin.23.2.53

[7] Yardley, J., Mollard, R. and MacIntosh, A. (2013) Vigorous Intensity Exercise for Glycemic Control in Patients with Type 1 Diabetes. Canadian Journal of Diabetes, 37, 427-432. https://doi.org/10.1016/j.jcjd.2013.08.269

[8] Yardley, J., Sigal, R. and Perkins, B. (2013) Resistance Exercise in Type 1 Diabetes. Canadian Journal of Diabetes, 37, 420-426. https://doi.org/10.1016/j.jcjd.2013.07.020

[9] Liu, X., Miller, Y., Burton, N. and Brown, W. (2010) A Preliminary Study of the Effects of Tai Chi and Qigong Medical Exercise on Indicators of Metabolic Syndrome, Glycaemic Control, Health Related Quality of Life and Psychological Health in Adults with Elevated Blood Glucose. British Journal of Sports Medicine, 44, 704-709. https://doi.org/10.1136/bjsm.2008.051144

[10] Liu, X., Miller, Y., Burton, N., Chang, H. and Brown, W. (2011) Predictors and Mediators of Qi-Gong Mind-Body Therapy and Diabetes Control: A Randomized Controlled Trial. American Journal of Preventive Medicine, 41, 152-158. https://doi.org/10.1016/j.amepre.2011.04.007

[11] Song, R., Ahn, S., Roberts, B.L., Lee, E.O. and Ahn, Y.H. (2009) Adhering to a Tai Chi Program to Improve Glucose Control and Quality of Life for Individuals with Type 2 Diabetes. Journal of Alternative and Complementary Medicine, 15, 627-632. https://doi.org/10.1089/acm.2008.0330

[12] Liu, X., Miller, Y., Burton, N. and Brown, W. (2008) A Preliminary Study of the Ef- 
fects of Tai Chi and Qigong Medical Exercise on Indicators of Metabolic Syndrome and Glycaemic Control in Adults with Raised Blood Glucose Levels. British Journal of Sports Medicine, 1-5. https://doi.org/10.1136/bjsm.2007.045476

[13] Liu, X. (2006) KaiMai Tai Ji. People’s Sports Publisher, Beijing, 46-137.

[14] Stanford Patient Education Center. Center for Epidemiologic Studies Short DepressiveSscale (CES-D10).

[15] Norton, K. and Olds, T. (2000) Anthropometrica-A Textbook of Body Measurement for Sports and Health Courses. University of New South Wales Press, Sydney, 35-37, 58.

[16] Australian Institute of Health and Welfare. Person-Blood Pressure (Systolic) (Measured), Millimetres of Mercury NN[N].

http://meteor.aihw.gov.au/content/index.phtml/itemId/270073

[17] Australian Institute of Health and Welfare. Person-Blood Pressure (Diastolic) (Measured), Millimetres of Mercury NN[N]. http://meteor.aihw.gov.au/content/index.phtml/itemId/270072

[18] Lin, M. and Ward, J.E. (1998) Reliability of the MOS SF-36 Health Status Measure in Australian General Practice. Australian Family Physician, 27, S94-S98.

[19] Rikli, R.E. and Jones, C.J. (2001) Senior Fitness Test Manual. Human Kinetics, Champaign, 61-62.

[20] Castaneda, C., Layne, J.E. and Orians, L.M. (2002) A Randomized Controlled Trial of Resistance Exercise Training to Improve Glycemic Control in Older Adults with Type 2 Diabetes. Diabetes Care, 25, 2335-2341. https://doi.org/10.2337/diacare.25.12.2335

[21] Dunstan, D.W., Daly, R.M. and Owen, N. (2002) High-Intensity Resistance Training Improves Glycemic Control in Older Patients with Type 2 Diabetes. Diabetes Care, 25, 1729-1736. https://doi.org/10.2337/diacare.25.10.1729

[22] Wang, F., Wang, W. and Zhang, R. (2008) Clinical Observation on Physiological and Psychological Effects of Eight-Section Brocade on Type 2 Diabetic Patients. Journal of Traditional Chinese Medicine, 28, 101-105. https://doi.org/10.1016/S0254-6272(08)60025-4

[23] International Diabetes Federation Western Pacific Region and the Asian-Pacific Type 2 Diabetes Policy Group (2005) Type 2 Diabetes: Practical Targets and Treatments. 4th Edition, The International Diabetes Institute, Melbourne, 43-44.

[24] McGill, M., Molyneaux, L., Twigg, S.M. and Yue, D.K. (2008) The Metabolic Syndrome in Type 1 Diabetes: Does It Exist and Does It Matter? Journal of Diabetes and its Complications, 22, 18-23. https://doi.org/10.1016/j.jdiacomp.2006.10.005 